\title{
SEED GERMINATION OF MASBEDDA (Gymnema sylvestre), A RARE MEDICINAL PLANT AS AFFECTED BY PH AND ORGANIC SOLVENTS
}

\author{
K KI U Arunakumara, S Subasinghe and W R T Rsanthi \\ Faculty of Agriculture, University of Ruhuna
}

The use of plants in treating diseases can be traced to the remote past. However due to lack of organized and scientific cultivation, proper management and awareness of social factors, the number of these medicinal plants is decreasing at an alarming rate. Gymnema sylvestre is one of rare medicinal plant species, which has high demand in the market. Since, little information is available on germination dynamics of Gymnema seeds, the present investigation was carried out to study the effect of $\mathrm{pH}$ and organic solvents on germination of Gymnema sylvestre seeds.

Fresh seeds taken from the plant were used for the experiment. Five pH solutions (i.e. $4,6,7,8$ and 10 ) were used to moist the filter papers in petri dishes, which contained seeds. A separate experiment was carried out to study the effect of organic solvents (i.e. Ethanol, Ether, Xylene, and Acetone) on germination following same procedure with using distilled water as a control. CRD was used in both experiments with 20 replicates each containing 10 seeds.

Results showed that significantly $(\mathrm{p}<0.05)$ higher germination of seeds $(56 \%$ and $52 \%)$ at $\mathrm{pH} 4$ and 6 respectively, whereas the lowest germination (36\%) showed at $\mathrm{pH} 10$. The highest germination (62\%) was recorded from the seeds treated with distilled water, followed by Xylene $(42 \%)$ and Ether $(39 \%)$. A significantly $(p<0.05)$ lower germination was showed in Acetone (10\%) and Ethanol (6\%). According to the findings of the experiment it can be concluded that slightly acidic media would be the best $\mathrm{pH}$ for the germination of Gymnema sylvestre seeds, whereas the organic solutions showed negative effects.

Proceedings of the Ninth Annual Forestry and Environment Symposium 2003 of the Department of Forestry and Environmental Science, University of Sri Jayewardenepura. Sri Lanka 